\title{
Reinforcement contexts effects on fixed-interval responding
}

\author{
R. J. MADIGAN \\ University of Alaska, Anchorage, Alaska 99504
}

\begin{abstract}
Three rats responding on fixed-interval schedules received either 1 or 4 pellets at the end of 2-min intervals. Five experimental conditions manipulated the relative probabilities of these two reinforcers. Response rates following the 1-pellet reinforcer were always higher than the rates following the 4-pellet reinforcer. The rates after the 1-pellet reinforcer were also highest in those experimental conditions where it was delivered with low probability. Contrast effects were observed when two sequential fixed intervals differed in reinforcer magnitudes. It was concluded that the context of reinforcement as well as the specific reinforcer magnitude affects responding under fixed-interval schedules.
\end{abstract}

When rats and pigeons respond for food reinforcement at fixed intervals (FI), their response patterns show a pause after reinforcement followed by an increase in responding (Ferster \& Skinner, 1957). This familiar scallop pattern produced by FI schedules is disrupted when a brief blackout is substituted for some of the scheduled reinforcements. Staddon and Innis $(1966,1969)$ found that reinforcement omission produced high rates of responding in the interval following nonreinforcement. Staddon $(1967,1972)$ has proposed that one effect of reinforcement on FI schedules is to produce a temporal inhibition of responding. He suggested that this inhibition creates the postreinforcement pause and the slowly increasing response rate characteristic of FI performance. In the absence of reinforcement, the inhibition does not occur and high rates of responding result. Staddon (1970) has demonstrated that temporal inhibition increases with the reinforcer magnitude. Pigeons responding on an FI 1-min schedule experienced variations in the magnitude of reinforcement delivered during an experimental session. Response rates varied inversely with the size of the preceding reinforcer: large amounts of reinforcement led to lower response rates than small amounts of reinforcement.

One important issue relevant to variations in the magnitude of reinforcement is whether these effects are relative or absolute (e.g., Black, 1968). Bevan (1963) and others (Bower, 1961; Helson, 1964) have suggested that the behavioral effect of a specific reinforcer magnitude depends on the set of previous

A portion of this experiment was presented at the Western Psychological Association Meetings, Sacramento, California, 1975. The author wishes to thank M. P. McKeown, J. Gargrave, and B. Sloan for their help in carrying out the experiment and Richard Bruce for a critical reading of the manuscript. Reprints are available from R. J. Madigan, Division of Social Sciences, University of Alaska, 3221 Providence Drive, Anchorage, Alaska 99504. reinforcer magnitudes experienced by the organism. A small reinforcer magnitude may produce one effect when it is delivered after a series of other small reinforcers and quite a different effect when it is embedded in a context of large reinforcers. Harzem, Lowe, and Davey (1975) have reported data which seem to show such a context effect. In one condition, rats were exposed to a fixed reinforcer magnitude under a FI 3-min schedule. Daily sessions continued until stable performance was observed and then a new magnitude of reinforcement was introduced. During the first three sessions, postreinforcement pausing was an increasing function of the magnitude of the new reinforcer; however, this effect disappeared with continued exposure to the reinforcer. Harzem et al. suggested that the organism must experience different reinforcer magnitudes closely in time for an orderly relation to emerge between reinforcer magnitude and the postreinforcer pause.

The present experiment also examined the effects of reinforcement context on the temporal inhibition produced by different magnitudes of reinforcement, but did so by manipulating the reinforcer context within single experimental sessions. The relative frequencies of the two reinforcer magnitudes were manipulated while an FI 2-min schedule remained in effect. Either a large or a small amount of food was dispensed after each interval. By varying the proportion of intervals which ended with each reinforcer, the average amount of reinforcement was varied without changing the reinforcer magnitudes. The purpose of the experiment was to examine reinforcerproduced temporal inhibition when the context of reinforcement was altered in this way.

\section{METHOD}

Subjects

Three naive, male rats, maintained at $80 \%$ of their free-feeding 
Table 1

The Experimental Conditions, Session Length, and Sessions per Condition

\begin{tabular}{|c|c|c|c|}
\hline \multicolumn{2}{|c|}{ Probability } & \multirow{2}{*}{$\begin{array}{l}\text { Fixed Intervals } \\
\text { per Session }\end{array}$} & \multirow{2}{*}{$\begin{array}{c}\text { Total } \\
\text { Sessions }\end{array}$} \\
\hline One Pellet & Four Pellets & & \\
\hline 1.00 & 0.00 & 30 & 51 \\
\hline 0.80 & 0.20 & 30 & 16 \\
\hline 0.50 & 0.50 & 22 & 21 \\
\hline 0.20 & 0.80 & 15 & 24 \\
\hline 0.00 & 1.00 & 15 & 38 \\
\hline
\end{tabular}

body weights, served as subjects. They were about 110 days old at the beginning of the experiment.

\begin{abstract}
Apparatus
The experimental space was $22 \mathrm{~cm}$ high $\times 22 \mathrm{~cm}$ wide $\times 30 \mathrm{~cm}$ deep and fitted with a single lever requiring $.075 \mathrm{~N}$ to depress. Two white stimulus lamps were located above and on either side of the lever. The experimental space was enclosed in a soundattenuating chamber. Reinforcement consisted of Noyes $45-\mathrm{mg}$ food pellets delivered by operating a standard food dispenser either once or four times. The left stimulus light was illuminated for $.5 \mathrm{sec}$ before the delivery of the 1-pellet reinforcer and the right light preceded the 4-pellet reinforcer.

\section{Procedure}

All subjects were magazine trained and then placed on an FI 2-min schedule, which remained in effect during all five conditions of the experiment. The probabilities of delivering the 1-pellet and the 4-pellet reinforcers were varied in the experimental conditions. The 1-pellet reinforcer was delivered with probabilities $1.00,0.80,0.50,0.20$, and 0.00 , respectively, in the five conditions, and the probabilities associated with the 4-pellet reinforcer were the complements $0.00,0.20,0.50,0.80$, and 1.00 . All three subjects were exposed to the experimental conditions in the same order. Each condition remained in effect until the overall response rates of all three rats were judged stable, after which an additional five sessions were run, which provided the data reported below.

The length of the daily sessions was adjusted to control for satiation effects in those conditions where many 4-pellet reinforcers were dispensed. The maximum number of pellets delivered in any daily session was 60 , which was about $25 \%$ of a subject's food intake. Table 1 lists the experimental conditions and the number of sessions per condition.
\end{abstract}

\section{RESULTS}

Response rates in intervals following large and small reinforcers were computed for each experimental condition by subject and are plotted in Figure 1 . Standard errors are indicated for each data point.

The response rate following a 1-pellet reinforcer was inversely related to its probability. In experimental conditions where 1-pellet reinforcers were less frequent, they were followed by a higher rate than in conditions where they were more frequent. The higher response rates in these conditions indicate a reduction in the temporal inhibition following the 1-pellet reinforcer. As the proportion of 4-pellet reinforcers delivered in a session was increased, the amount of temporal inhibition produced by the 1-pellet reinforcer decreased. The response rates following a 4-pellet reinforcer are difficult to summarize. The mean rate following a large reinforcer was always less than the mean rate after a small reinforcer. However, there was no simple relation between these response rates and the experimental conditions.

Figure 2 shows response rates as a function of the two most recent reinforcers for those experimental conditions which mixed 1- and 4-pellet reinforcement. The response rate in interval $\mathrm{n}$ was computed conditional on the reinforcers dispensed after intervals $n-1$ and $n-2$. Standard errors for each data point are not shown in this figure, but the median standard error for each rat is given to show typical variability.

Figure 2 presents data separately for individual experimental conditions and for the average of three conditions. Figure 2 shows that a 1-pellet reinforcer after interval $n-1$ produced a higher response rate in interval $n$ than a 4-pellet reinforcement. Figure 2 also shows that the reinforcer after interval $n-2$ affected the response rate in interval $n$. A 1-pellet reinforcer in interval $n-1$ typically produced the largest increase in rate when it had been preceded in interval $n-2$ by a 4-pellet reinforcer. Similarly, a 4-pellet reinforcer in interval $n-1$ produced the

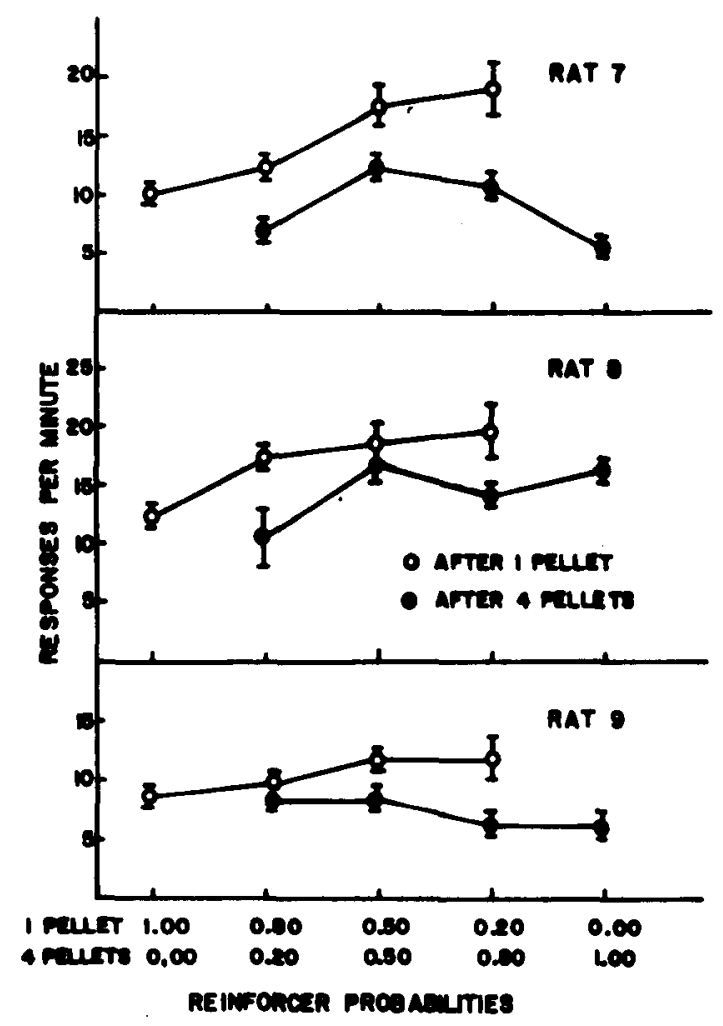

Figure 1. Response rates after 1-pellet reinforcers and 4-pellet reinforcers for each experimental condition. 


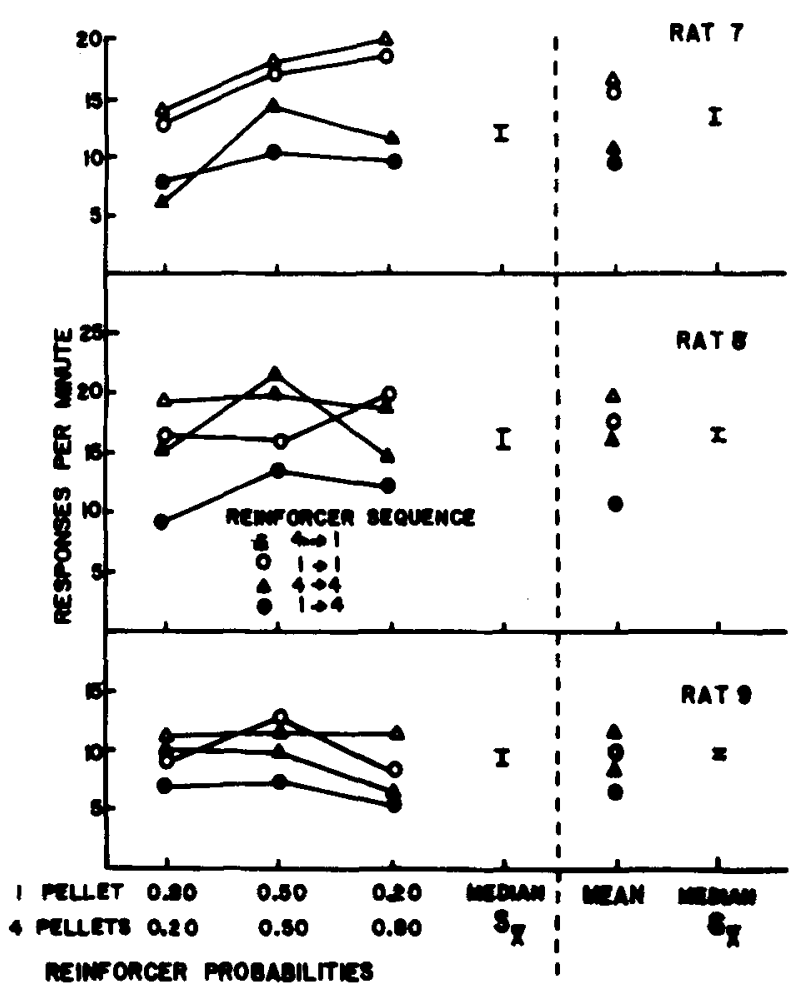

Figure 2. Response rates as a function of the two most recent reinforcers for experimental conditions mixing 1- and 4-pellet reinforcement.

largest decrease in rate when a 1 -pellet reinforcer was delivered in interval $n-2$. It appears that a transition from one reinforcer magnitude to another produced a contrast effect. This pattern is consistent for all three subjects in the data averaged across conditions.

A second analysis of sequential dependencies is given in Figure 3, where the ef fects of each reinforcer magnitude are depicted for several intervals following its delivery. Response rates were computed for intervals $n+1, n+2, n+3$, and $n+4$, given that a specific reinforcer magnitude had occurred after interval $n$. The response rate in interval $n+1$ will be affected by the specific reinforcer magnitude delivered after interval $n$, as demonstrated in Figures 1 and 2 . Here it was determined whether or not this effect extended to intervals $n+2, n+3$, and $n+4$. This analysis was performed on the data from the $50 / 50$ condition, in which each reinforcer was delivered with equal frequency.

The computation of response rates in these intervals was accomplished as follows. Consider the case where it is desired to compute the response rate in interval $n+2$, given that a 1-pellet reinforcer was dispensed after interval $n$. There were two possible sequences which met this condition, one sequence which had a 1-pellet reinforcer after interval $n+1$ and another which had a 4-pellet reinforcer after interval $n+1$. These two types of sequence did not necessarily occur with equal frequency. In order to obtain an unbiased estimate of the response rate in interval $n+2$, first the response rate was computed separately for each reinforcer sequence and then the final estimate of the response rate was made by taking an unweighted average of the two rates. This procedure prevented the estimate of the response rate in interval $n+2$ from being biased by imbalances in the distribution of reinforcer magnitudes occurring after interval $n+1$. If the 1 -pellet reinforcer delivered after interval $n$ had no effect on responding in interval $n+2$, the computed response rate in this interval would be an estimate of the overall response rate during the session.

Response rates for intervals $n+3$ and $n+4$ were calculated in a similar way. A separate determination of response rate was made for each possible sequence of intervening reinforcer magnitudes, and the final estimate was the unweighted average of these rates. In order to avoid obscuring the figure, standard errors are plotted only for response rates following a 1-pellet reinforcer. These data showed more
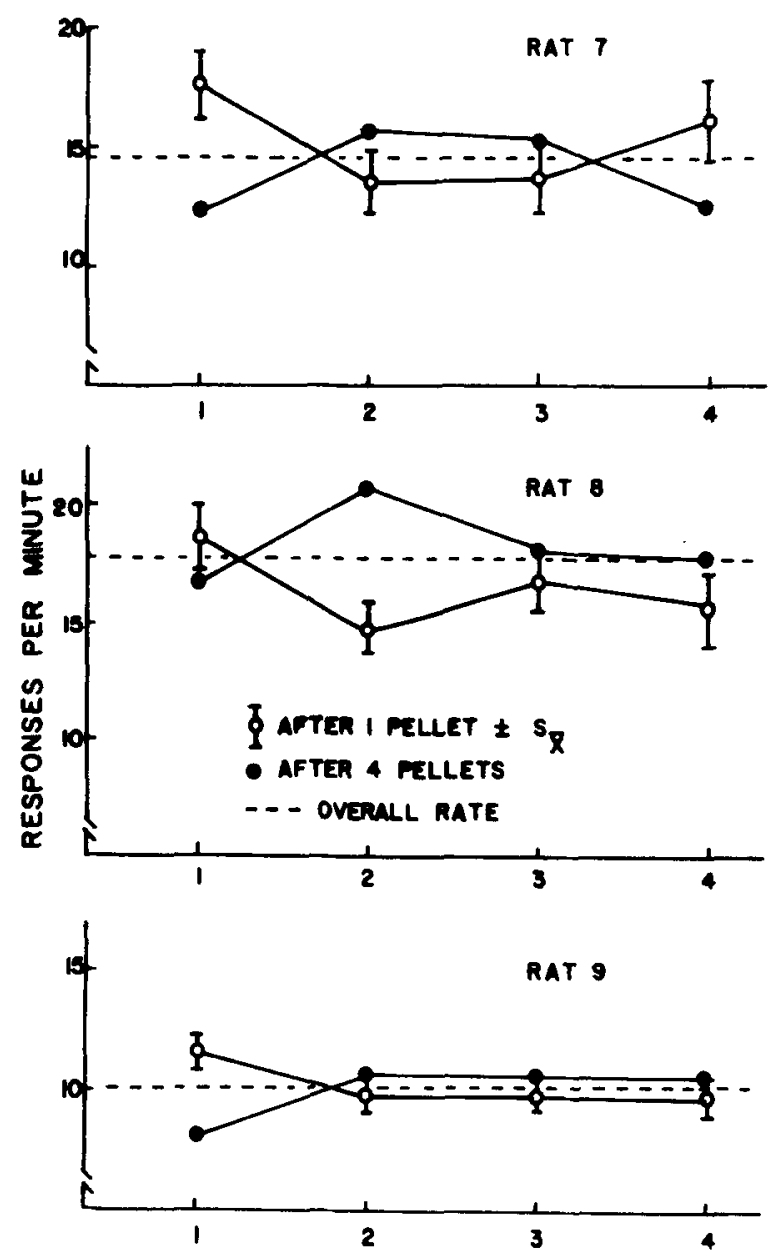

INTERVALS FOLLOWING REINFORCEMENT

Figure 3. Response rates in the intervals following 1-pellet and 4-pellet reinforcers. 
variability than rates following 4 pellets, so the standard errors plotted conservatively estimate the variability of the other data.

The data in Figure 3 show an interesting shift of effects. In the case of a 1-pellet reinforcer delivered after interval $n$, the immediate effect was to increase the rate in interval $n+1$ above the average session rate. However, in intervals $n+2$ and $n+3$, the rate was lower than average. This was consistent for all three subjects, although the effect was small for rat 9 . By interval $n+4$ there was no consistent effect.

When a 4-pellet reinforcer was delivered in interval $n$, it produced a rate reduction in interval $n+1$ and then a rate increase in intervals $n+2$ and $n+3$. There was no consistent pattern in response rates at interval $n+4$.

It appears that the effects of a 1-pellet and a 4-pellet reinforcer extended beyond the intervals following their delivery, and that their remote effects on response rates were in a direction opposite to their immediate effects.

\section{DISCUSSION}

This experiment replicated Staddon's (1970) finding that large reinforcer magnitudes lead to lower response rates than small magnitudes. Jensen and Fallon (1973) have also reported a similar result. They exposed rats to a two-component, multiple FI FI schedule in which the reinforcer magnitude was manipulated in the first component. Their data showed that the response rate in the second component varied inversely with the reinforcer magnitude delivered in the first component. A related finding has been reported by Carr and Reynolds (1974), who placed pigeons on a multiple reinforcement schedule where FI 3 min alternated with the differential reinforcement of other behavior (DRO). The DRO schedule was in effect for $3 \mathrm{~min}$ and delivered food whenever the pigeon had not pecked the key for a specified time, $t$. By varying $t$, Carr and Reynolds manipulated the number of times reinforcement occurred in the 3-min DRO period. They found that response rate in the FI component varied inversely with the number of reinforcers collected in the preceding DRO component. These studies and the present one support the conclusion that the inhibition of FI responding increases with the amount of immediately preceding reinforcement.

The purpose of the present experiment was to investigate the effect of the reinforcement context on the amount of temporal inhibitions produced by two different reinforcer magnitudes. Figure 1 showed that the context produces strong effects. Bevan (1963, p. 24) has argued that the "effectiveness" of a reinforcer is not fixed but varies with the magni- tude of the preceding reinforcers. He proposed a fluctuating adaptation level (Helson, 1964) for reinforcement which was based on previous reinforcer and which determined the effectiveness of the next reinforcement. The data presented here support a relative view of reinforcer magnitude. The effect of a given reinforcer magnitude on response rate can be altered by the context of reinforcement preceding it. Response rate following the small reinforcer increased as the probability of this reinforcer decreased. Variations in the probability of the large reinforcer also affected subsequent response rates.

Context effects were present within experimental conditions as well as between conditions. Figure 2 showed strong contrast effects. The 4-pellet reinforcer produced the greatest amount of response inhibition when it had been preceded by a 1-pellet reinforcer, and the 1-pellet reinforcer produced the least amount of inhibition when it followed a 4-pellet reinforcer. Meltzer and Howerton (1973, Experiment 2) have reported similar contrast effects when 1- and 3-pellet reinforcers were mixed within FI 3-min sessions. Some of the differences between experimental conditions were probably due to these contrast effects. For example, in the condition where the 1-pellet reinforcer was delivered with probability 0.20 , it was usually preceded by a 4-pellet reinforcer, while in the condition where it was delivered with probability 0.80 , it was usually preceded by another 1-pellet reinforcer. The contrast effects in the 0.20 condition would tend to elevate the response rates following this reinforcer relative to those in the 0.80 condition. This line of reasoning predicts a monotonic increase in response rates following a 1-pellet reinforcer across experimental conditions as the probability of this reinforcer decreased and contrast effects became more likely. This was observed for all three subjects. The same reasoning, however, predicts a similar monotonic increase in response rates following the 4-pellet reinforcer across experimental conditions, and this was not observed.

Perhaps the most unexpected finding was that the immediate effects of each reinforcer magnitude were different from the delayed effects (see Figure 3). A small reinforcer first produced an increase in response rate during the interval immediately following it but then a decrease in rate during the second interval. A similar, but opposite, effect was found after the large reinforcer. For two subjects, these effects are small and should be viewed as tentative pending replication. However, the empirical issue is an important one, namely, the duration of effects produced by variations in the magnitude of reinforcement. The reversal of effects in the second interval following a reinforcer may be a delayed effect of the reinforcer or it may be the immediate effect of the response rate in the first interval following the rein- 
forcer. The present experiment confounds these two variables. Ferster and Skinner (1957, pp. 167-168) have suggested that high rates of responding in one fixed interval tend to produce low rates in the next, and, conversely, low rates tend to be followed by high rates. This might explain the data of Figure 3, although neither Carr and Reynolds (1974) nor Dews (1970) found Ferster and Skinner's relationship in the responses of pigeons on FI schedules.

\section{REFERENCES}

Bevan, W. The pooling mechanism and the phenomena of reinforcement. In $\mathrm{O}$. J. Harvey (Ed.), Motivation and social interaction. New York: Ronald Press, 1963.

BLACK, R. W. Shifts in magnitude of reward and contrast effects in instrumental and selective learning: A reinterpretation. Psychological Review, 1968, 75, 114-126.

BowER, G. H. A contrast effect in differential conditioning. Journal of Experimental Psychology, 1961, 62, 196-199.

CARR, E. G., \& ReYnolds, G. S. Temporal inhibition: effects of changes in rate of reinforcement and rate of responding. Joumal of the Experimental Analysis of Behavior, $1974,22,73-81$.

DEws, P. B. The theory of fixed-interval responding. In W. N. Schoenfeld (Ed.), The theory of reinforcement schedules. New York: Appleton-Century-Crofts, 1970.

Ferster, C. B., \& Skinner, B. F. Schedules of reinforcement. New York: Appleton-Century-Crofts, 1957.
Harzem, P., Lowe, C. F., \& Davey, G. C. L. After effects of reinforcer magnitude: Dependence upon context. In Quarterly Journal of Experimental Psychology, 1975, 27, 579-584.

Helson, H. Adaptation-level theory. New York: Harper \& Row, 1964.

JENSEN, C., \& FALLON, D. Behavioral aftereffects of reinforcement and its omission as a function of reinforcement magnitude. Journal of the Experimental Analysis of Behavior. $1973,19,459-468$.

Meltzer, D., \& Howerton, D. L. Sequential effects of reinforcement magnitude on fixed-interval performance in rats. Journal of Comparative and Physiological Psychology, 1973, 85, 361-366.

Staddon, J. E. R. Attention and temporal discrimination: Factors controlling responding under a cyclic-interval schedule. Journal of the Experimental Analysis of Behavior, 1967, 10, 349-359.

Staddon, J. E. R. Effect of reinforcement duration on fixedinterval responding. Journal of the Experimental Analysis of Behavior, 1970, 13, 9-11.

Staddon, J. E. R. Temporal control and the theory of reinforcement schedules. In R. M. Gilbert \& J. R. Millenson (Eds.), Reinforcement: Behavioral analyses. New York: Academic Press, 1972.

Staddon, J. E. R., \& Innis, N. K. An effect analogous to "frustration" on interval reinforcement schedules. Psychonomic Science, 1966, 4, 287-288.

StAddon, J. E. R., \& InNIS, N. K. Reinforcement omission on fixed-interval schedules. Joumal of the Experimental Analysis of Behavior, 1969, 12, 689-700.

(Received for publication December 14, 1976; revision accepted November 30,1977 .) 